\title{
STUDI ON-STREET PARKING DI RUAS JALAN BRIGJEND SLAMET RIYADI (SIMPANG EMPAT PASAR PON - SIMPANG EMPAT GENDENGAN) KOTA SURAKARTA
}

\author{
Rake Adiuto $^{1)}$, Budi Yulianto ${ }^{2)}$, Amirotul Mahmudah H.M. ${ }^{3)}$ \\ 1) Mahasiswa Program S1 eknik Sipil, Universitas Sebelas Maret \\ 2)3) Pengajar Program Studi Teknik Sipil, Universitas Sebelas Maret \\ Jalan Ir. Sutami No. 36 A Surakarta 57126. Telp: (0271) 647069. Email: rakeadiuto@gmail.com
}

\begin{abstract}
Surakarta as a big city has a large vehicle population, where in there some business centers, shopping, and offices have high level of parking usage, one of them is located in Brigjend Slamet Riyadi Street. Moreover, the government will implement contra-flow system for BST bus in the street, from Pasar Pon four way-intersection to Gendengan four way-intersection. Through analytical study of the parking characteristics of on-street parking in Brigjend Slamet Riyadi Street (Pasar Pon four way-intersection-Gendengan four way-intersection), the data obtained from analytical data are volume, parking accumulation, average parking duration, static capacity, parking index, dinamic capacity, parking turnover, parking activity index, and service level (V/C ratio). The data indicate that the location has several parking problems such as insufficient parking space and high duration parking usage, causing a lot of illegal parking spaces. The recommendations of the parking policy on these issues are in the form of restrictions on parking duration, redesigned parking to $0^{\circ}$ angle (paralel), and alternative priority of BST bus transportation with contra-flow system, are given. For several location, the use of off-street parking also needed.
\end{abstract}

Key word: parking usage, contra flow system, parking characteristics, average parking duration, parking index, redesigned parking.

Abstrak

Surakarta sebagai kota besar mempunyai populasi kendaraan yang besar, dimana di beberapa pusat bisnis, perbelanjaan, dan perkantoran memiliki tingkat penggunaan parkir yang tinggi, salah satunya berlokasi di jalan Brigjend Slamet Riyadi. Selain itu, pemerintah akan menerapkan sistem contra-flow untuk bus BST di jalan tersebut, dari arah Bundaran Gladag sampai ke Simpang Empat Gendengan. Melalui studi analisis karakteristik parkir on-street di Jalan Brigjend Slamet Riyadi (Simpang Empat Pasar Pon-Simpang Empat Gendengan), didapat data analisis yaitu volume, akumulasi, rata-rata durasi, kapasitas statis, kapasitas dinamis, indeks parkir, pergantian parkir, indeks aktifitas parkir, dan tingkat pelayanan (V/C ratio). Data tersebut menunjukkan bahwa di lokasi tersebut memiliki beberapa masalah parkir diantaranya ruang parkir yang kurang mencukupi dan penggunaan parkir dengan durasi waktu tinggi, sehingga menyebabkan banyaknya ruang parkir ilegal. Diberikan rekomendasi kebijakan atas permasalahan tersebut berupa pembatasan durasi parkir, desain ulang parkir ke sudut $0^{\circ}$ (paralel), dan prioritas alternatif transportasi bus BST dengan sistem contra-flow. Untuk beberapa lokasi, penggunaan parkir off-street juga diperlukan.

Kata kunci : penggunaan parkir, sistem contra-flow, karakteristik parkir, rata-rata durasi, indeks parkir, desain ulang parkir.

\section{PENDAHULUAN}

Sebagai kota besar, Surakarta memiliki populasi kendaraan yang besar. Berdasarkan www.harianjogja.com pada 24 Mei 2017, Unit Pelayanan Pendapatan Daerah (UPPD) atau Samsat Solo mencatat jumlah kendaraan baru di Solo selama Januari-April bertambah 5.473 unit. Rata-rata jumlah kendaraan baru Solo 1.500 unit per bulan. Hal ini menyebabkan jalan raya di Surakarta sangat padat kendaraan, terutama pada jam sibuk.

Jalan Slamet Riyadi (Simpang Empat Gladag - Simpang Tiga Purwosari) adalah jalan yang memiliki klasifikasi fungsi sebagai jalan arteri utama Kota Surakarta. Di sepanjang jalan ini terdapat berbagai pusat bisnis, perbelanjaan, dan pariwisata, sehingga sehingga pada jam puncak terjadi kepadatan lalu lintas. Kepadatan lalu lintas tersebut juga dipengaruhi oleh parkir on-street yang ada di sepanjang jalan. Pada jam-jam tertentu slot parkir tersebut penuh hingga sampai menggunakan pinggiran jalan yang seharusnya tidak diperbolehkan. 
Seiring dengan kebijakan pemerintah yang akan membuat jalan Slamet Riyadi menjadi contra-flow untuk bus Batik Solo Trans (BST) melawan arah arus lalu lintas dari Gladag sampai ke Gendengan, salah satunya pernyataan dari Kepala Unit Pelaksana Daerah (UPTR) Perparkiran, M. Usman di website http://joglosemar.co pada 5 Desember 2016, adanya rencana penerapan contra-flow dari Gladag-Gendengan, pihaknya akan menata ulang parkir di tepi jalan sepanjang Jalan Slamet Riyadi.

Dari permasalahan tersebut, analisis karakterisitik parkir di sepanjang Jalan Slamet Riyadi ini perlu dilakukan, mengingat kebijakan contra-flow yang akan diterapkan. Melalui studi ini diharapkan dapat memberikan hasil analisis karakteristik parkir di Jalan Slamet Riyadi (Simpang Empat Pasar Pon-Simpang Empat Gendengan) sesuai dasardasar transportasi sebagai data pertimbangan untuk kebijakan contra-flow yang akan diterapkan.

Penelitian tentang perparkiran sebelumnya telah dilakukan oleh beberapa peneliti, seperti Evriyani dkk (2016), Patel, dkk (2016), Arishandi dkk. (2017), Thanh, dkk (2016), Wahdan, dkk (2014), Borovskoy, dkk (2016), dan Dedy (2016). Penelitian-penelitian ini mencari dan mempelajari tentang kebutuhan dan kondisi pelayanan parkir, berserta rekomendasi solusi atas permasalahannya. Perbedaan penelitian ini dengan penelitian Evriyani dkk (2016) dan Arishandi dkk (2017) adalah perbedaan lokasi parkir (off-street). Perbedaan penelitian dengan Patel dkk (2016) terletak pada analisis model deskriptif dan statistik, serta survei dengan kuesioner, sedangkan penelitian ini menggunakan survei patroli. Perbedaan dengan penelitian Thanh dkk (2016) adalah fokusnya ke parkir ilegal, sedangkan penelitian fokus ke karakteristik parkirnya. Perbedaan penelitian dengan Wahdan dkk (2014) adalah lokasi survei dan rekomendasi masalahnya. Perbedaan penelitian dengan Borovskoy dkk (2016) adalah metode analisis datanya menggunakan aplikasi Vehicle Tracking. Perbedaan penelitian dengan Dedy (2016) adalah fokusnya sistem contra-flow dengan parkir on-street sebagai parameter yang berpengaruh, sedangkan penelitian ini berfokus ke karakteristik parkir on-street dengan penerapan sistem contra-flow. Secara umum, penelitian ini dilakukan dengan tujuan selain untuk mengetahui karakteristik parkir pada daerah lokasi penelitian, juga mempertimbangkan kebijakan yang diambil dari karakteristik parkir tersebut, dimana dilakukan perbaikan sistem parkir yang berhubungan dengan pelaksanaan rencana sistem contra-flow untuk bus BST.

\section{DASAR TEORI}

\section{Karakteristik Parkir}

Karakteristik parkir digambarkan dalam bentuk parameter-parameter berikut ini :

\section{Volume Parkir}

Volume parkir adalah jumlah keseluruhan kendaraan yang menggunakan fasilitas parkir, biasanya dihitung dalam kendaraan yang parkir dalam satu hari (Abubakar, 1998). Volume parkir dihitung menggunakan rumus:

Volume $=\mathrm{Nin}+\mathrm{X}$

Dimana:

Nin = Jumlah kendaraan yang masuk (kendaraan).

$X \quad=$ Kendaraan yang sudah ada sebelum waktu survei (kendaraan).

\section{Rata-rata Lamanya (Durasi) Parkir}

Rata- rata durasi parkir adalah rata-rata lama waktu yang dipakai setiap kendaraan untuk berhenti pada ruang parkir yang dinyatakan dalam jam/kendaraan. Rata-rata lamanya parkir dari seluruh kendaraan selama waktu survei dapat diketahui dari rumus (Oppenlender, 1976) :

$\mathrm{D}=\frac{\sum(\mathrm{Nx}) \cdot(\mathrm{X}) \cdot(\mathrm{I})}{(\mathrm{Nt})}$

Dimana :

$\mathrm{D}=$ Rata - rata lama parkir $/$ durasi $(\mathrm{jam} / \mathrm{kend})$.

$\mathrm{Nx} \quad=$ Jumlah kendaraan yang parkir selama interval waktu survei (kend.).

$\mathrm{X}=$ Jumlah dari interval.

I $\quad=$ Interval waktu survei (jam).

$\mathrm{Nt} \quad=$ Jumlah total kendaraan selama waktu survei. 


\section{Indeks Parkir (IP)}

Indeks parkir adalah perbandingan antara akumulasi parkir dengan kapasitas parkir yang menunjukkan seberapa besar kapasitas parkir yang telah terisi. Besaran indeks parkir ini akan menunjukkan apakah kawasan parkir tersebut bermasalah atau tidak (Putu Alit Suthayana, 2010). Rumus yang dapat digunakan unutuk menghitung indeks parkir adalah :

Indeks Parkir $=\frac{\text { Akumulasi Parkir }}{\text { Kapasitas Statis Parkir }}$

Dengan pengertian angka Indeks Parkir (IP):

$\mathrm{IP}<1$ = fasilitas parkir tidak bermasalah, dimana kebutuhan parkir tidak melebihi daya tampung/ kapasitas normal.

IP $=1=$ kebutuhan parkir seimbang dengan daya tampung/kapasitas normal.

IP $>1$ = fasilitas parkir bermasalah, dimana kebutuhan parkir melebihi daya tampung $/$ kapasitas normal.

\section{METODE PENELITIAN}

\section{Survei Pengumpulan Data}

Pada penelitian ini ada dua macam data yang dikumpulkan data primer dan data sekunder. Data primer adalah data pokok yang didapatkan langsung di lokasi survei berupa waktu durasi parkir kendaraan di lokasi, jenis dan plat nomor kendaraan, serta ukuran dimensi parkir. Data sekunder didapatkan dari data yang sudah ada dan wawancara dengan pihak terkait, berupa denah lokasi parkir, fakta lapangan, serta informasi pendukung lain.

\section{Lokasi Penelitian}

Lokasi dilakukannya studi adalah Jalan Slamet Riyadi dari Simpang Empat Pasar Pon sampai di Simpang Empat Gendengan. Dari lokasi tersebut dibagi menjadi tiga ruas, yaitu Simpang Pasar Pon-Simpang Ngapeman, Simpang Ngapeman-Simpang Sriwedari, Simpang Sriwedari-Simpang Gendengan.

\section{Waktu Penelitian}

Pengambilan data survey ini dilakukan pada hari kerja (Senin-Jumat) pukul 13.00-18.00 WIB.

\section{Prosedur Penelitian}

Rencana penerapan jalur sistem contra-flow di Jalan Brigjend Slamet Riyadi memerlukan berbagai studi dan rekayasa lalu lintas dan jalan, salah satunya adalah studi karakteristik parkir untuk mengetahui permasalahan parkir yang ada. Masalah-masalah yang ditemui dalam penelitian dirumuskan menjadi rumusan masalah, kemudian dalam pelaksanaan studi penelitian diberi batasan-batasan sehingga menjadi fokus dan terarah. Kemudian ditentukan tujuan dari studi penelitian tersebut yang didasarkan pada masalah-masalah yang telah dirumuskan.

Setelah rumusan masalah dan tujuan telah ditentukan, dilakukan survei pendahuluan, dalam studi penelitian ini adalah dengan meninjau lokasi parkir dan melakukan wawancara terhadap para juru parkirnya. Survei pendahuluan ini dilakukan untuk mendapatkan data yang berpengaruh terhadap penelitian mengenai lokasi parkir tersebut.

Data yang didapat pada survei pendahuluan kemudian dijadikan acuan untuk pengambilan data utama. Pada pengambilan data utama ini ada dua macam data yang dikumpulkan. Data yang pertama adalah data primer, yaitu data pokok didapatkan langsung di lokasi survei. Data primer yang dikumpulkan berupa desain survey, waktu durasi parkir kendaraan di lokasi, jenis dan plat nomor kendaraan, dan ukuran dimensi parkir. Data yang kedua adalah data sekunder yaitu data yang sudah ada dan hasil wawancara dengan pihak terkait, berupa denah lokasi parkir, fakta lapangan, dan informasi-informasi lain.

Data perolehan survei yang diperoleh kemudian diolah menggunakan perhitungan yang telah ditentukan, kemudian di analisis untuk mengetahui hubungan antara data dengan masalah yang telah dirumuskan. Dalam tahapan analisis, parameter-parameter karakteristik yang dicari adalah volume parkir, akumulasi parkir, durasi 
parkir, indeks parkir, kapasitas statis parkir, kapasitas dinamis parkir, parking turnover, indeks aktifitas parkir, dan $\mathrm{V} / \mathrm{C}$ ratio.

Dari hasil analisis diperoleh karakteristik on-street parking yang menggambarkan kondisi eksisting yang ada di dalam lokasi parkir tersebut. Permasalahan yang ada kemudian di berikan rekomendasi solusi parkir, dengan mempertimbangkan sistem contra-flow yang akan diterapkan.

\section{ANALISIS DATA DAN PEMBAHASAN}

\section{Analisi Data Karakteristik Parkir}

Analisis data karakteristik parkir dilakukan terhadap dua jenis kendaraan yaitu sepeda motor dan mobil (mobi penumpang dan barang), yang kemudian masing masing dibagi menjadi kendaraan yang parkir secara legal dan ilegal. Untuk ruas jalan Simpang Empat Ngapaman - Simpang Tiga Sriwedari dan Simpang Tiga Sriwedari Simpang Empat Gendengan tidak ada sepeda motor yang parkir..

Berikut Gambar 1 merupakan grafik rata-rata durasi kendaraan sepeda motor per segmen dalam satu ruas untuk ruas jalan Simpang Empat Pasar Pon-Simpang Empat Ngapeman.

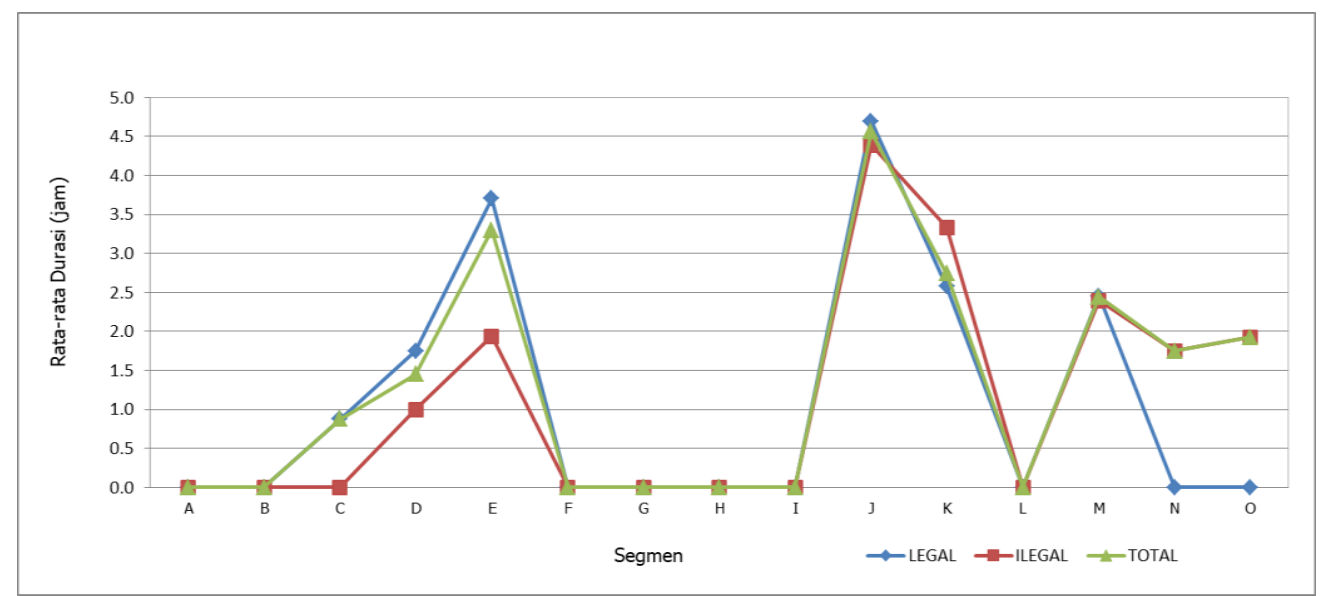

Sumber: Hasil Analisis

Gambar 1. Grafik Rata-rata Durasi Kendaraan Sepeda Motor Per Segmen dalam Satu Ruas untuk Ruas jalan Simpang Empat Pasar Pon-Simpang Empat Ngapeman

Berikut Gambar 2 merupakan grafik rata-rata durasi kendaraan mobil per segmen dalam satu ruas untuk ruas jalan Simpang Empat Pasar Pon-Simpang Empat Ngapeman.

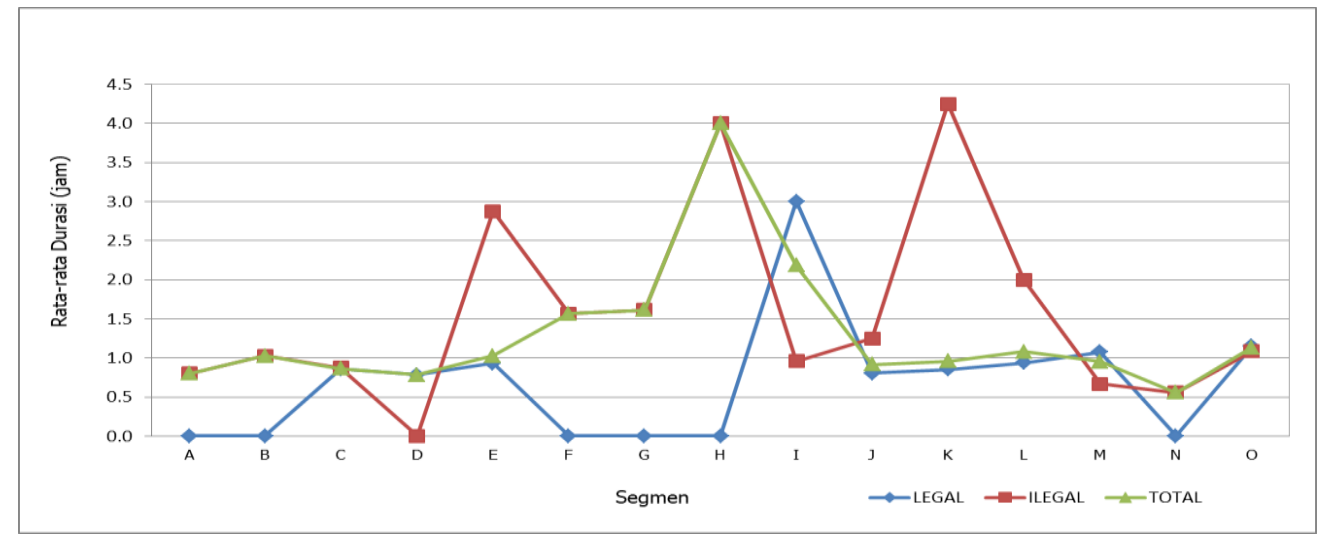

Sumber: Hasil Analisis

Gambar 2. Grafik Rata-rata Durasi Kendaraan Mobil Per Segmen dalam Satu Ruas untuk Ruas jalan Simpang Empat Pasar Pon-Simpang Empat Ngapeman

Data dari grafik Gambar 1 dan Gambar 2 ditampilkan rata-rata dalam satu ruas, ditunjukkan pada Tabel 1 berikut. 
Tabel 1. Rata-rata Durasi Parkir dalam Satu Ruas (jam/kendaraan) untuk Ruas jalan Simpang Empat Pasar PonSimpang Empat Ngapeman (Jam/Kendaraan)

\begin{tabular}{ccc}
\hline Ruang Parkir & Motor & Mobil \\
\hline Legal & 2,89 & 1,00 \\
\hline Ilegal & 2,42 & 1,05 \\
\hline Legal \&Ilegal & 2,73 & 1,02 \\
\hline
\end{tabular}

Sumber: Hasil Analisis

Berikut Gambar 3 merupakan grafik rata-rata durasi kendaraan mobil per segmen dalam satu ruas untuk ruas jalan Simpang Empat Ngapeman-Simpang Tiga Sriwedari.

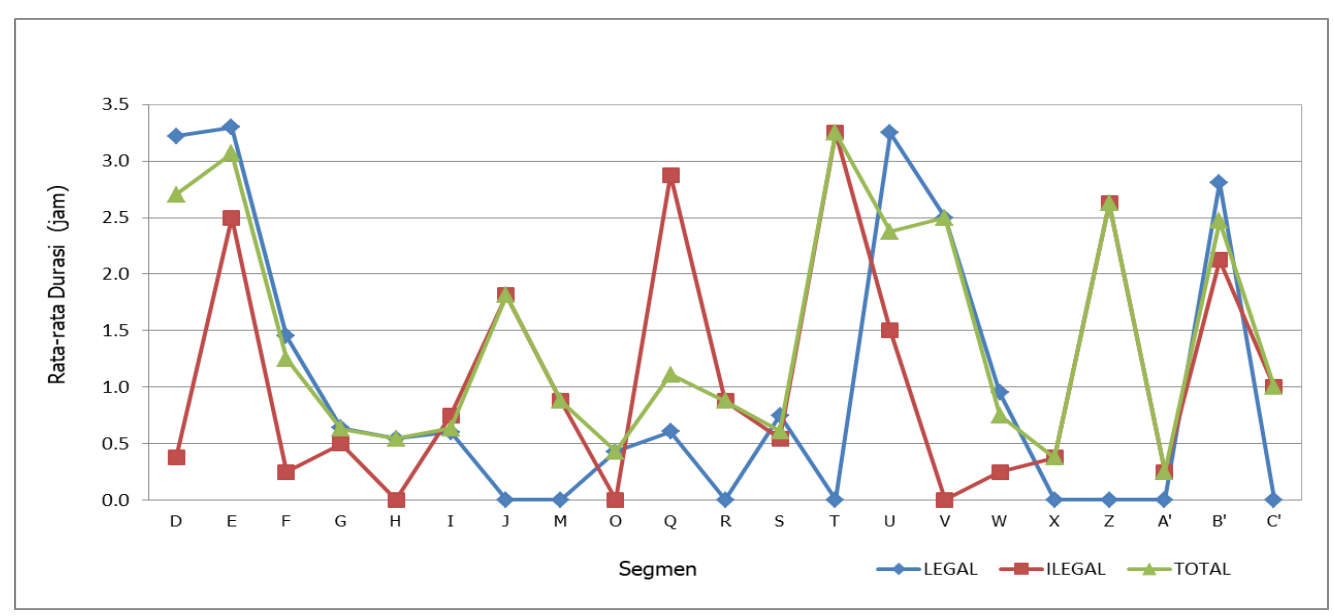

Sumber: Hasil Analisis

Gambar 3. Grafik Rata-rata Durasi Kendaraan Mobil Per Segmen dalam Satu Ruas untuk Ruas jalan Simpang Empat Ngapeman - Simpang Tiga Sriwedari

Data dari grafik Gambar 3 kemudian ditampilkan rata-rata dalam satu ruas, ditunjukkan pada Tabel 2 berikut.

Tabel 2. Rata-rata Durasi Parkir dalam Satu Ruas untuk Ruas jalan Simpang Empat Ngapeman - Simpang Tiga Sriwedari (jam/kendaraan)

\begin{tabular}{cc}
\hline Ruang Parkir & Mobil \\
\hline Legal & 1,17 \\
\hline Ilegal & 1,23 \\
\hline Legal \&Ilegal & 1,19 \\
\hline
\end{tabular}

Sumber: Hasil Analisis

Berikut Gambar 4 merupakan grafik rata-rata durasi kendaraan mobil per segmen dalam satu ruas untuk ruas Simpang Tiga Sriwedari-Simpang Empat Gendengan. 


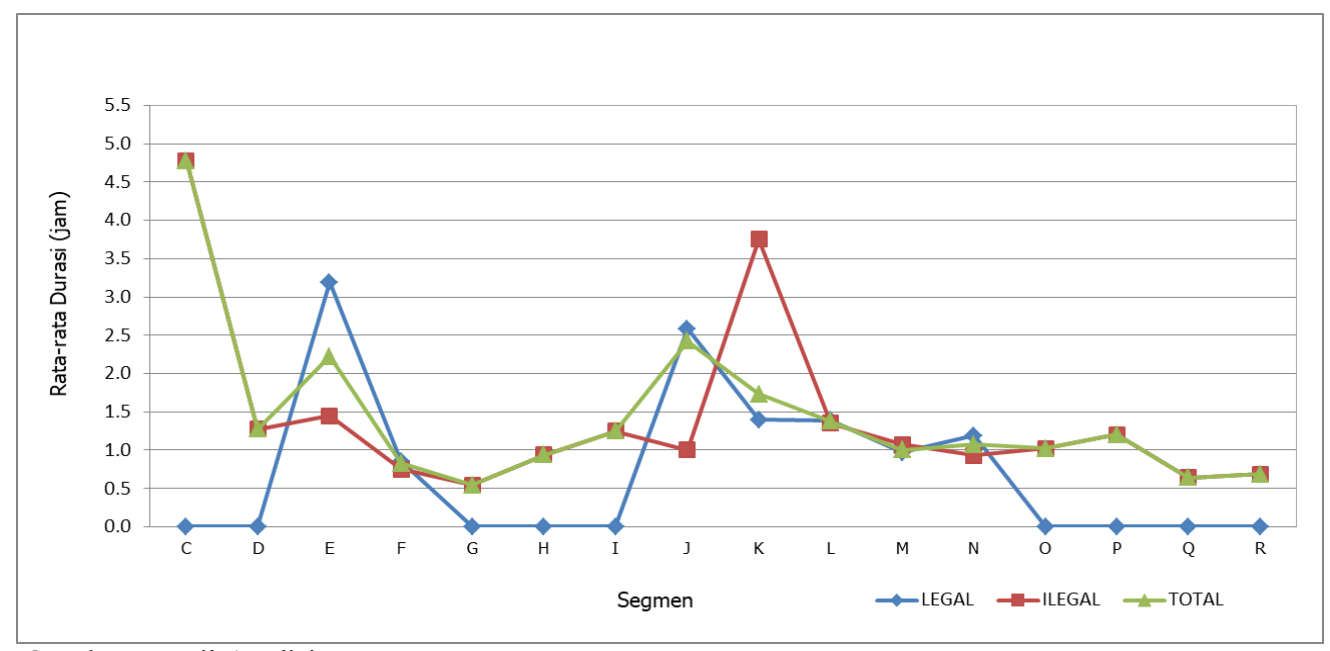

Sumber: Hasil Analisis

Gambar 4. Grafik Rata-rata Durasi Kendaraan Mobil Per Segmen dalam Satu Ruas untuk Ruas jalan Simpang Tiga Sriwedari - Simpang Empat Gendengan

Data dari grafik Gambar 4 ditampilkan rata-rata dalam satu ruas, ditunjukkan pada Tabel 3 berikut.

Tabel 3. Rata-rata Durasi Parkir dalam Satu Ruas untuk Ruas jalan Simpang Tiga Sriwedari - Simpang Empat Gendengan (jam/kendaraan)

\begin{tabular}{ccc}
\hline Ruang Parkir & Mobil \\
\hline Legal & 1,38 \\
\hline Ilegal & 1,40 \\
\hline Legal \&Ilegal & 1,39 \\
\hline
\end{tabular}

Sumber: Hasil Analisis

Hasil analisis karakteristik parkir kemudian ditampilkan di dalam rangkuman Tabel 4, 5, dan 6.

Tabel 4. Karakteristik Parkir Ruas jalan Simpang Empat Pasar Pon- Simpang Empat Ngapeman

\begin{tabular}{lcc}
\hline \multirow{2}{*}{ Parameter } & Sepeda Motor & Mobil \\
\cline { 2 - 3 } & Eksisting & Eksisting \\
\hline Kapasitas Statis Total (Legal) & 157 & 97 \\
\hline Indeks Parkir & 0,61 & 0,55 \\
\hline Pergantian Parkir & 0,22 & 0,54 \\
\hline Kapasitas Dinamis & 287,4 & 475,92 \\
\hline IAP & 0,05 & 0,29 \\
\hline$V / C$ ratio & 0,61 & 0,55 \\
\hline Subr
\end{tabular}

Sumber: Hasil Analisis

Tabel 5. Karakteristik Parkir Ruas jalan Simpang Empat Ngapeman - Simpang Tiga Sriwedari

\begin{tabular}{cc}
$*$ \\
Parameter & Mobil \\
\cline { 2 - 3 } & Eksisting
\end{tabular}

\begin{tabular}{lc}
\hline Kapasitas StatisTotal (Legal) & 103 \\
\hline Indeks Parkir & 0,37 \\
\hline Pergantian Parkir & 0,31 \\
\hline Kapasitas Dinamis & 433,54 \\
\hline IAP & 0,1 \\
\hline$V / C$ ratio & 0,37 \\
\hline Sumber: Hasil Analisis &
\end{tabular}


Tabel 6. Karakteristik Parkir Ruas jalan Simpang Tiga Sriwedari - Simpang Empat Gendengan

\begin{tabular}{lc}
\multicolumn{1}{c}{ Parameter } & Mobil \\
\cline { 2 - 2 } & Eksisting \\
\hline Kapasitas Statis & 97 \\
\hline Indeks Parkir & 0,80 \\
\hline Pergantian Parkir & 0,58 \\
\hline Kapasitas Dinamis & 348,3 \\
\hline IAP & 0,33 \\
\hline$V / C$ ratio & 0,8 \\
\hline
\end{tabular}

Sumber: Hasil Analisis

\section{Rekomendasi Perbaikan Masalah}

Berdasarkan analisis di atas, diketahui terdapat ruang parkir dengan kendaraan yang parkir memiliki rata-rata durasi lebih dari 4 jam. Pengguna dengan durasi parkir yang lama ini kebanyakan merupakan pegawai dari toko maupun kantor yang berada di jalan tersebut. Selain itu karena ruang parkir digunakan secara terus-menerus dengan durasi lama, penempatan kendaraan parkir seringkali menempati lokasi yang seharusnya tidak diperuntukkan untuk parkir (ilegal). Oleh karena hal ditersebut, maka dilakukan alternatif solusi yaitu pembatasan durasi parkir menjadi 2 jam.

Pembatasan durasi parkir menjadi 2 jam akan membuat pegawai mencari alternatif lain sebagai transportasi. Salah satu alternatif yang diharapkan menjadi pilihan adalah dengan menggunakan BST. Pelaksanaan BST ini juga diikuti dengan penerapan contra-flow, sehingga dapat menjangkau tujuan baik ke arah barat dan timur Jalan Brigjend Slamet Riyadi.

Pelaksanaan sistem contra-flow menggunakan sebagian area jalan, yang mengurangi kapasitas kendaraan di jalan tersebut. Salah satu solusi untuk mengganti sebagian area yang digunakan untuk contra-flow BST adalah dengan membuat parkir yang semula memiliki sudut $60^{\circ}$ diubah menjadi paralel atau $0^{\circ}$. Selain itu pengubahan sudut ruang parkir ini juga diiringi dengan penyesuaian lokasi parkir yang legal. Hal ini tentu membuat kapasitas parkir menjadi berkurang.

Tabel 7, 8, dan 9 berikut merupakan tabel berisi perbandingan karakteristik parkir jalan (on-street) eksising $60^{\circ}$ di tiga ruas dengan setelah diubah menjadi paralel atau bersudut $0^{\circ}$.

Tabel 7 Perbandingan Karakteristik Parkir Ruas Jalan Simpang Empat Pasar Pon - Simpang Empat Ngapeman

\begin{tabular}{lcccccc}
\hline \multirow{2}{*}{ Parameter } & \multicolumn{3}{c}{ Sepeda Motor } & \multicolumn{3}{c}{ Mobil } \\
\cline { 2 - 7 } & Sudut $60^{\circ}$ & Paralel & Perubahan (\%) & Sudut $60^{\circ}$ & Sudut $0^{\circ}$ & Perubahan (\%) \\
\hline $\begin{array}{l}\text { Kapasitas Statis Total } \\
\text { (Legal) }\end{array}$ & 157 & 75 & $-52,2$ & 97 & 29 & $-70,1$ \\
\hline Indeks Parkir & 0,61 & 1,28 & 109,8 & 0,55 & 1,83 & 232,7 \\
\hline Pergantian Parkir & 0,22 & 0,47 & 113,6 & 0,54 & 1,81 & 233,9 \\
\hline Kapasitas Dinamis & 287,4 & 137,29 & $-52,2$ & 475,92 & 142,28 & $-70,1$ \\
\hline IAP & 0,05 & 0,22 & 340 & 0,29 & 3,25 & 1019,3 \\
\hline$V / C$ ratio & 0,61 & 1,27 & 108,2 & 0,55 & 1,84 & 234,5 \\
\hline
\end{tabular}

Sumber: Hasil Analisis

Tabel 8 Perbandingan Karakteristik Parkir Ruas Jalan Simpang Empat Ngapeman - Simpang Tiga Sriwedari

\begin{tabular}{llll}
\hline \multirow{2}{*}{ Parameter } & \multicolumn{3}{c}{ Mobil } \\
\cline { 2 - 4 } & Sudut $60^{\circ}$ & Sudut $0^{\circ}$ & Perubahan (\%) \\
\hline
\end{tabular}




\begin{tabular}{lccc}
\hline Kapasitas StatisTotal (Legal) & 103 & 36 & $-65,05$ \\
\hline Indeks Parkir & 0,37 & 1,07 & 189,2 \\
\hline Pergantian Parkir & 0,31 & 0,89 & 187,1 \\
\hline Kapasitas Dinamis & 433,54 & 151,53 & $-65,05$ \\
\hline IAP & 0,1 & 0,81 & 710 \\
\hline$V / C$ ratio & 0,37 & 1,06 & 186,5 \\
\hline S
\end{tabular}

Sumber: Hasil Analisis

Tabel 9 Perbandingan Karakteristik Parkir Ruas Jalan Simpang Tiga Sriwedari - Simpang Empat Gendengan

\begin{tabular}{cccc}
\hline \multirow{2}{*}{ Parameter } & \multicolumn{3}{c}{ Mobil } \\
\cline { 2 - 4 } & Sudut $60^{\circ}$ & Sudut $0^{\circ}$ & Perubahan $(\%)$ \\
\hline Kapasitas Statis & 97 & 28 & $-71,1$ \\
\hline Indeks Parkir & 0,80 & 2,78 & 247,5 \\
\hline Pergantian Parkir & 0,58 & 1,99 & 238,9 \\
\hline Kapasitas Dinamis & 348,3 & 100,54 & 71,1 \\
\hline IAP & 0,33 & 3,98 & 1106 \\
\hline V/C ratio & 0,8 & 2,78 & 247,5
\end{tabular}

Sumber: Hasil Analisis

Di dalam Tabel 7, 8, dan 9 dijelaskan perbandingan karakteristik antara parkir eksisting $60^{\circ}$ tiga ruas dengan kondisi setelah sudut parkir dibuat menjadi $0^{\circ}$. Terdapat penurunan kapasitas statis parkir yang ada sebesar $50 \%$ sampai $70 \%$. Hal ini disebabkan selain parkir $0^{\circ}$ menggunakan panjang parkir horizontal yang lebih panjang, dilakukan pula penyesuaian terhadap lokasi parkir on-street yang benar-benar diijinkan (tanpa lokasi parkir ilegal). Pengurangan terhadap kapasitas parkir yang ada tidak mencukupi kebutuhan parkir yang terjadi, ditandai dengan angka Indeks Parkir yang melebihi angka 1.

Berdasarkan permasalahan diatas maka dibuat pembatasan durasi parkir menjadi 2 jam. Tabel 10, 11, dan 12 berikut merupakan perbandingan antara karakteristik parkir jalan (on-street) eksising $60^{\circ}$ tiga ruas dengan setelah diubah menjadi paralel atau bersudut $0^{\circ}$ dan pengurangan parkir yang melebihi 2 jam.

Tabel 10 Perbandingan Karakteristik Parkir Ruas Jalan Simpang Empat Pasar Pon - Simpang Empat Ngapeman

\begin{tabular}{lcccccc}
\hline \multirow{2}{*}{ Parameter } & \multicolumn{3}{c}{ Sepeda Motor } & \multicolumn{3}{c}{ Mobil } \\
\cline { 2 - 7 } & Sudut $60^{\circ}$ & Paralel & Perubahan (\%) & Sudut $60^{\circ}$ & Sudut $0^{\circ}$ & Perubahan (\%) \\
\hline $\begin{array}{l}\text { Kapasitas Statis Total } \\
\text { (Legal) }\end{array}$ & 157 & 67 & $-61,71$ & 97 & 231 & $-11,83$ \\
\hline Indeks Parkir & 0,61 & 75 & $-52,229$ & 0,55 & 29 & $-70,103$ \\
\hline Pergantian Parkir & 0,22 & 0,13 & $-77,923$ & 0,54 & 1,02 & 84,639 \\
\hline Kapasitas Dinamis & 287,4 & 0,18 & $-18,788$ & 475,92 & 1,59 & 195,02 \\
\hline IAP & 0,05 & 510,15 & 77,506 & 0,29 & 224,56 & $-52,6$ \\
\hline$V / C$ ratio & 0,61 & 0,03 & $-34,536$ & 0,55 & 231 & $-11,83$ \\
\hline Sur & & & & & & \\
\hline
\end{tabular}

Sumber: Hasil Analisis

Dari Tabel 10 diatas dijelaskan bahwa pembatasan durasi parkir menjadi 2 jam membuat kapasitas untuk menampung kebutuhan parkir sepeda motor tercukupi ditandai dengan Indeks Parkir dibawah angka 1, namun untuk kebutuhan parkir mobil masih belum mencukupi (dengan parameter Indeks parkir 1,02). Kurang cukupnya kapasitas untuk mobil ini dapat diatasi dengan solusi alternatif lain, salah satunya adalah dengan me-intensifkan penggunaan parkir luar badan jalan (off-street) dan penyelenggaraan sarana gedung parkir.

Tabel 11 Perbandingan Karakteristik Parkir Ruas Jalan Simpang Empat Ngapeman - Simpang Tiga Sriwedari

\begin{tabular}{lccc}
\hline \multirow{2}{*}{ Parameter } & \multicolumn{3}{c}{ Mobil } \\
\cline { 2 - 4 } & Sudut $60^{\circ}$ & Sudut $0^{\circ}$ & Perubahan (\%) \\
\hline Volume & 161 & 135 & $-16,15$ \\
\hline
\end{tabular}




\begin{tabular}{lccc}
\hline Kapasitas Statis Total (Legal) & 103 & 36 & $-65,05$ \\
\hline Indeks Parkir & 0,37 & 0,49 & 31,381 \\
\hline Pergantian Parkir & 0,31 & 0,75 & 141,93 \\
\hline Kapasitas Dinamis & 433,54 & 282,56 & $-34,82$ \\
\hline IAP & 0,1 & 0,57 & 472,311 \\
\hline V/C ratio & 0,37 & 0,27 & $-27,39$ \\
\hline
\end{tabular}

Sumber: Hasil Analisis

Dari Tabel 11 diatas dijelaskan bahwa pembatasan durasi parkir menjadi 2 jam membuat kapasitas untuk menampung kebutuhan parkir mobil tercukupi ditandai dengan Indeks Parkir dibawah angka 1.

Tabel 11 Perbandingan Karakteristik Parkir Mobil Ruas Jalan Simpang Tiga Sriwedari - Simpang Empat Gendengan

\begin{tabular}{lccc}
\hline \multirow{2}{*}{ Parameter } & \multicolumn{2}{c}{ Mobil } \\
\cline { 2 - 4 } & Sudut $60^{\circ}$ & Sudut $0^{\circ}$ & Perubahan (\%) \\
\hline Volume & 279 & 222 & $-20,43$ \\
\hline Kapasitas Statis Total (Legal) & 97 & 28 & $-71,13$ \\
\hline Indeks Parkir & 0,8 & 1,3 & 62,05 \\
\hline Pergantian Parkir & 0,58 & 1,59 & 173,4 \\
\hline Kapasitas Dinamis & 348,3 & 171,95 & $-50,632$ \\
\hline IAP & 0,33 & 2,52 & 665,13 \\
\hline V/C ratio & 0,8 & 1,29 & 61,38 \\
\hline S
\end{tabular}

Sumber: Hasil Analisis

Dari tabel 11 diatas dijelaskan bahwa pembatasan durasi parkir menjadi 2 jam masih membuat kapasitas kebutuhan parkir mobil belum tercukupi (dengan parameter Indeks parkir 1,3). Kurang cukupnya kapasitas untuk mobil ini dapat diatasi dengan solusi alternatif lain, salah satunya adalah dengan penggunaan parkir luar badan jalan (off-street) dan penyelenggaraan sarana gedung parkir.

\section{SIMPULAN}

Berdasarkan hasil analisis dan pembahasan, maka dapat diambil kesimpulan sebagai berikut:

1. Kondisi pelayanan parkir on-street di Jalan Brigjend Slamet Riyadi (Simpang Empat Pasar Pon-Simpang Empat Gendengan) belum optimal, dapat diketahui dari karakteristik parkir berikut:

- Indeks parkir dan $\mathrm{V} / \mathrm{C}$ ratio tinggi: $>1$

- Banyaknya slot (ruang parkir/kapasitas statis) ilegal.

- Parking turnover rendah $<1$

- Banyaknya kendaraan parkir dengan durasi lebih dari 2 jam.

2. Rekomendasi sebagai langkah perbaikan sistem parkir on-street dalam hubungannya dengan sistem contraflow:

- Penyesuaian sudut parkir dari semula $60^{\circ}$ menjadi $0^{\circ}$ (paralel) dan penempatan ruang parkir yang benar-benar diijinkan. Kemudian dilakukan pembatasan durasi parkir, sehingga membuat pegawai atau pengguna parkir dengan durasi lama untuk mencari alternatif lain, salah satunya dengan BST bersistem contra-flow dan sistem antar jemput.

- Penggunaan parkir luar badan jalan (off-street) dan penyelenggaraan gedung parkir untuk ruas Simpang Empat Pasar Pon - Simpang Empat Ngapeman dan ruas Simpang Tiga Sriwedari Simpang Empat Gendengan.

\section{SARAN}

Saran yang diberikan pada studi ini adalah sebagai berikut. 
1. Dilakukan kajian lebih lanjut tentang kebijakan sistem pembatasan durasi parkir, termasuk sistem pembayaran parkir, dan penegakan hukumnya.

2. Dilakukan studi lebih lanjut dalam alternatif solusi tentang penggunaan parkir off-street dan penentuan lokasi sarana gedung parkir untuk ruas yang membutuhkan.

\section{DAFTAR PUSTAKA}

Abubakar, I, dkk. (1998). Pedoman Perencanaan dan Pengoperasian Fasilitas Parkir. Jakarta: Direktorat Bina Sistem Lalu Lintas dan Angkutan Kota Direktorat Jenderal Perhubungan.

Arishandi, N.G., Suthanaya, P.A., dan Wedagama, D.M.P., 2017. Analisis Karakteristik dan Kebutuhan Parkir Terminal Kargo di Kota Denpasar. Universitas Udayana : Jurnal Spektran. Vol. 5, No.1 : 1-87.

Borovskoy, A. dan Yakovleva, E., 2017. Simulation Model of Parking Spaces Through the Example of the Belgorod Agglomeration. Transportation Research Procedia, 20, pp.80-86.

Departemen Perhubungan Direktur Jenderal Perhubungan Darat. (1996). Pedoman Teknis Penyelenggaraan Fasilitas Parkir. Jakarta.

Evriyani, D., Nahry, dan Soehodho, S., 2014. Kajian Analisis Karakteristik Parkir Off-street Kendaraan Angkutan Barang dan Pengantaran Barang di Pusat Perbelanjaan Pasar Jatinegara. The 17th FSTPT International Symposium. Universitas Jember. Jember.

Hobbs, F.D., 1995. Perencanaan dan Teknik Lalu Lintas Edisi Kedua. Yogyakarta: Gadjah Mada University Press.

Hakim, N.L., 2016. 20 Bus Baru Siap, Contra Flow Slamet Riyadi Diterapkan Awal Tahun. Diambil dari: http://joglosemar.co/2016/12/20-bus-baru-siap-contra-flow-slamet-riyadi-diterapkan-awal-tahun.html

Hartono, D.I., Yulianto, B. and Mahmudah, A.M., 2016. Kajian Sistem Contra Flow Bus Lanes di Jalan Brigjend Slamet Riyadi Surakarta. Matriks Teknik Sipil, 4(4).

Ismail, M., 2017. 4 Bulan, Ada Tambahan 5.473 Unit Kendaraan Baru di Solo. Diambil dari: http://www.harianjogja.com/baca/2017/05/24/4-bulan-ada-tambahan-5-473-unit-kendaraan-baru-disolo-819230

Kementrian PPN/Bappenas. 2015. Toolkit untuk Mobilitas Perkotaan di Indonesia Manajemen Parkir di Perkotaan. Jakarta.

O'Flaherty, C. ed., 1997. Transport planning and traffic engineering. Elsevier.

Patel, M. dan Dave, S., 2016. Modeling the response to paid on street parking policy for two wheelers and four wheelers on busy urban streets of CBD area-A case study of Surat city. Transportation Research Procedia, 17, pp.576-585.

Pemerintah Republik Indonesia. 2009. Undang-Undang No. 22 Tahun 2009 Tentang Lalu Lintas dan Angkutan Jalan.

Thanh, T.T.M. dan Friedrich, H., 2017. Legalizing the illegal parking, a solution for parking scarcity in developing countries. Transportation Research Procedia, 25, pp.4954-4969.

Wahdan, Y., Farida, I. dan Permana, S., 2016. Analisis Karakteristik Parkir Pada Badan Jalan dan Dampaknya Terhadap Lalu Lintas (Studi Kasus: Jalan Siliwangi Kabupaten Garut). Jurnal Konstruksi, 12(1). 